\title{
Nature-Based Solutions for Coastal Engineering and Management
}

\author{
Jill Slinger $1,2, * \mathbb{D}$, Marcel Stive ${ }^{3, *}$ and Arjen Luijendijk ${ }^{3,4}$ \\ 1 Faculty of Technology, Policy and Management, Delft University of Technology, Jaffalaan 5, \\ 2628 BX Delft, The Netherlands \\ 2 Institute for Water Resources, Rhodes University, Artillery Road, Makhana 6140, South Africa \\ 3 Faculty of Civil Engineering and Geosciences, Delft University of Technology, Stevinweg 1, \\ 2628 CN Delft, The Netherlands; arjen.luijendijk@deltares.nl \\ 4 Deltares, Boussinesqweg 1, 2629 HV Delft, The Netherlands \\ * Correspondence: j.h.slinger@tudelft.nl (J.S.); m.j.f.stive@tudelft.nl (M.S.)
}

Citation: Slinger, J.; Stive, M.;

Luijendijk, A. Nature-Based Solutions

for Coastal Engineering and

Management. Water 2021, 13, 976.

https://doi.org/10.3390/w13070976

Received: 29 March 2021

Accepted: 31 March 2021

Published: 1 April 2021

Publisher's Note: MDPI stays neutral with regard to jurisdictional claims in published maps and institutional affiliations.
There is a growing scientific and engineering interest in exploring how natural processes can provide management solutions to resolve the degradation and vulnerability of coastal environments. Climate change and associated sea level rise together with drivers, such as subsidence, reduced sediment supply and coastal squeeze represent major risk factors for coastal systems sustainability. Using natural processes to deal with these risk factors presents a nontrivial challenge. This special issue focuses on nature-based solutions and state-of-the-art interventions in the coastal environment. The scene is set by a review paper that defines coastal resilience, claiming that Building with Nature approaches are intrinsic to achieving resilience [1]. All authors concur that nature-based solutions provide a means of meeting nature restoration goals as well as addressing socio-economic needs [1-13]. While one article evaluates the cost effectiveness of a particular solution [6], a critically reflective article compares nature-based solutions with conventional engineering solutions, distinguishing four axes, two of which relate to the inclusion of multiple stakeholders and ecological knowledge [5]. The majority of articles echo the need for both engineering and ecological knowledge in the design process, and two actively involve stakeholders in their analyses $[11,13]$. There are six articles that include the design of a (hybrid) nature-based solution $[2,4,6,9,10,13]$, while five articles undertake interdisciplinary experiments and measurements in the laboratory, the field, or via modeling to ascertain the performance of nature-based solutions [2,3,7-9]. A number of contributions focus on environmentally friendly Integrated Coastal Management (ICM), with two articles identifying factors most beneficial to ICM [11,12]. The study sites range from dunes to sandy coasts, and from muddy mangrove-dominated environments to vast lagoon systems in South America, Europe, Asia, and Africa. An overview of the contribution of each of the articles in this special issue to advancing the knowledge and practice of nature-based solutions in coasts is provided hereafter.

Masselink and Lazarus [1] define resilience as the capacity of the socioeconomic and natural systems in the coastal environment to cope with disturbances, induced by factors such as sea level rise, extreme events and human impacts, by adapting whilst maintaining their essential functions. They conclude from their literature review that coasts with essential ecological components such as salt marshes, mangroves, dunes, and coral reefs, lend themselves to applications of resilience principles for management. Indeed, in their view, nature-based solutions are central to achieving resilience and they contend that this requires more than engineering alone. They further indicate that measures that focus on increasing "resilience across all aspects of the coastal human-environmental system are costly and rare, and perhaps only Building with Nature approaches qualify" [1].

Van der Spek et al. [2] concur, following a Building with Nature approach to design an innovative sandbar breakwater, a nature-based solution for ports inspired by a constructed breakwater at Lekki in Nigeria. Along the Gulf of Guinea, West Africa, there is plentiful 
sand in the coastal zone and ports are subject to heavy sedimentation on the up-drift side of the breakwaters and rapid burial of (costly) armour rock. The sandbar breakwater relies on this inevitable accretion of sand on the up-drift side, in a sandbar, meaning that less rock and concrete units are needed compared with a conventional breakwater. The local natural coastal dynamics formed the starting point for the Building with Nature design process and the conceptual design was then tested using numerical and physical models. The unconventional geometry of the breakwater means that it is arguably better in wave sheltering than a comparable conventional design. The nature-based solution includes a maintenance and monitoring program to guarantee the ongoing safety of the sandbar breakwater and the navigability of the access channel, and to counteract shoreline retreat on the down-drift side of the port by means of sand nourishment. Given the suitability of the sandbar breakwater as nature-based port solution for coasts with unidirectional alongshore sediment transport, the authors suggest that it could also act as inspiration for more variable sandy coastal environments.

Most beaches on sandy coasts are backed by dunes with the composite beach-dune system providing a natural protection against flooding and acting as a buffer against erosion by storm waves. Instead of fixed and highly managed dune rows, Castelle et al. [3] focus on restoration of the natural dynamics at Truc Vert on the French Atlantic coast so as to provide the microhabitat and landscape diversity necessary for enhanced coastal biodiversity. They evaluate a pilot project, analyzing preliminary tests on the reinstatement of natural dynamics in reprofiled coastal dunes. Further vegetation monitoring, aeolian sand transport measurements and morphological surveys at Truc Vert, and at other coastal dune settings in Southwest France, are deemed necessary to provide more insight into the influence of natural processes reinstatement on overall coastal dune response and resilience. They conclude that although reinstating natural processes is desirable, it does not guarantee nature restoration, nor does increased landscape diversity guarantee increased plant and animal species diversity. This can take decades, particularly in dunes.

In their review of the literature, Scheres and Schüttrumpf [4] focus on sea dikes identifying that there is potential for their ecological enhancement through nature-based solutions in the foreshore and adapted dike surface protections and/or changed dike geometry. While nature-based solutions in the foreshore have received attention, there is little attention in the literature for ecological enhancements of the dike structure itself. They categorize methods for dike structure enhancement such as vegetated or colonized revetments and identify that technical uncertainties remain related to performance, implementation and efficiency. In identifying these as constituting interdisciplinary challenges for engineers and ecologists, they support the claim of Masselink and Lazarus [1] that more than engineering alone is required.

Indeed, Slinger and Vreugdenhil [5] adopting a critical reflection method focused on the design process, indicate that ecological knowledge is critical. In seeking to establish the degree to which a hydraulic infrastructure forms a nature-based solution, they distinguish four axes, namely:

- The degree of inclusion of ecological knowledge;

- The extent to which the full infrastructural lifecycle is addressed;

- The complexity of the actor arena taken into account;

- The resulting form of the infrastructural artefact.

They categorize conventional and new sea defense infrastructures on the North and South Holland coasts in terms of these axes, and indicate how nature-based the newly implemented solutions are, and how broadly societal values and stakeholders are taken into account in the design process. Engineers and scientists are called upon to apply this categorization so that the shift towards interdisciplinary nature-based design becomes apparent.

Verhagen [6] also compares conventional and nature-based solutions using an example from the muddy coast of Haldia in India. He makes a direct financial comparison between the classical solution of a dike with revetment and a solution with a mangrove belt in front of the dike, demonstrating that constructing a mangrove forest in front of a revetment 
decreases the construction costs by a larger amount than the planting and maintenance costs of the mangrove forest. No additional ecosystem benefits are included in the comparison, indicating that for high value, surge prone areas like low lying coastal cities or intensive agriculture, nature-based solutions are better for the environment but may also be more flexible and cheaper.

A low cost alternative suitable for application along muddy coasts are brushwood fences. Brushwood fences comprising bamboo and tree branches have been applied as nature-based solutions in the protection of eroding shorelines and mangrove forests along the Mekong Delta coast. The paper by Dao et al. [7] combines experimental work in a laboratory setting with field work in the Mekong Delta to explore the efficacy of the brushwood fences in wave-current dissipation. For this study, fence samples with porosities varying from $62 \%$ to about $90 \%$ were installed in both a model- and a full-scale set-up in inhomogeneous and staggered configurations. The flow resistance was established by determining the hydraulic gradient under stationary flows. The experimental results indicate that the bulk drag coefficient is strongly dependent on the fence's porosity, the minimum spacing ratio of the configuration (smallest distance that generates the highest turbulence conditions), and the Reynolds number. With decreasing drag coefficient, the Reynolds number increased and then became stable at values in excess of 1000 . The drag coefficient also decreased when the minimum spacing ratio was decreased in all the fullscale tests. This supports the inference that the lowest percentage porosity case has the smallest drag coefficient. The spaces between bamboo branches in brushwood fences are irregular, making the flow reduction somewhat unpredictable. However, a new method for predicting the bulk drag coefficient of wooden fences in the field is developed that makes use of the relationship between drag coefficient and the turbulent friction coefficient.

Drawing on flume experimental data related to wave attenuation by vegetated foreshores, the research by Niazi et al. [8] sought to deepen understanding of the parameters influencing wave attenuation by mangroves and salt marshes. A stochastic model of these ecosystem effects was developed using nonparametric Bayesian networks (NPBNs) to capture the dependence amongst the variables of interest. By modeling salt marsh and mangrove systems stochastically, a holistic system-based response to variations in individual variables was obtained. The NPBNs proved capable of generating physically realistic, yet diverse boundary conditions that are useful for cross-disciplinary system-based sensitivity analysis and filling information in data-scarce environments. Results indicate that when the generated boundary conditions are applied in hydrodynamic modeling studies, the bulk simulation time decreases and the authenticity of the overall system response increases. Fundamental to this type of modeling is the inclusion of bio-geomorphological knowledge that goes beyond standard modeling efforts by engineers alone.

Biogeomorphological knowledge is intrinsic to the approach of Muller et al. [9] who followed a Building with Nature approach to port development in Tongzhou Bay on the Jiangsu coast of the People's Republic of China. Tongzhou Bay is the site of large-scale land reclamations and ongoing development. It is an area of extensive intertidal mudflats supporting many species, including several endangered migratory shorebirds. The deep tidal channels intersecting the mudflats mean that the area also has aquaculture potential and that the construction of a deep-sea port is considered. Solutions that not only allow for port development, but also enhance the natural growth of valuable habitat were sought. Using bird spatial distributional data in combination with hydro-morphodynamic modeling, the preferred ecotopes of two endangered shorebird species, the Great Knot Calidris tenuirostris and the Bar-tailed Godwit Limosa lapponica were characterized in terms of inundation frequency, salinity and silt content and their distribution determined under different port designs. The simulation results showed clear differences in siltation patterns, and in the preservation and enhancement of the preferred ecotopes. This provides valuable input to decision making on port designs and demonstrates the contribution of morphological and habitat suitability modeling in the design of large-scale reclamations and port constructions, especially in dynamic areas such as Tongzhou Bay. Indeed, the authors emphasize the need 
for multidisciplinary cooperation between different disciplines from the outset to ensure more successful outcomes in terms of sustainability and societal support.

Similarly, Maiolo et al. [10] are motivated by the need for concerted action to preserve the ecosystems and biodiversity of the Mediterranean Sea. They report on a stepwise approach to restore the environment at Calabaia Beach in Italy while protecting existing assets. Long term adaptation strategies envisaged by the EUROSION project as alternative long-term regional responses to climate change and the increased threat of coastal erosion are reinterpreted by Maiolo et al. [10] as steps in a sequential approach culminating in nature-based solutions. This means that they see the severe erosion of the Calabaia Beach in the last century as the outcome of a (i) do nothing strategy. This is followed by a (ii) hold the line strategy in which several sea-defenses were constructed at the beach, followed by a (iii) move seaward strategy comprising a submerged breakwater and groynes (built using material taken from the former structures) as well as a perched sand nourishment. Finally, a nature-based solution viewed as a (iv) limited intervention strategy is planned. This includes the introduction and monitoring of indigenous seagrass beds. Planting of Posidonia oceanica at Calabaia Beach will be achieved by grafting seeds and cuttings onto biodegradable films, containing all the necessary nutrients, and anchoring these to the seabed. This nature-based solution is viewed as the final step in the restoration of ecosystem function in addition to the protection of humans and assets.

Baltranaite et al. [11] are also concerned with sustainable coastal management. They investigate the factors necessary for successful application of a systems approach in ICM implementation, particularly in the Baltic States and Kaliningrad Oblast of Russia. The systems approach is defined as an iterative process of issue-oriented, multidisciplinary inquiry, requiring a holistic rather than a reductionist, single discipline orientation and integrating the three pillars of sustainable development, namely environmental protection, social progress and economic growth. Specifically, the perceived credibility and usefulness of the broad-scale multidisciplinary scientific knowledge and methods of the systems approach at the regional level in Estonia, Latvia, Lithuania, and the Kaliningrad Oblast of the Russian Federation are investigated. A retrospective analysis of twenty completed and ongoing ICM case studies from all nine Baltic Sea countries was undertaken, covering diverse coastal themes. Strengths-Weaknesses-Opportunities-Threats (SWOT) analyses were carried out for each case study, as well as an analysis of the benefits that could be derived from a systems approach. Five principal components were found to explain over $84 \%$ of the total variance in the multivariate analysis of the case study data. These are: Stakeholder Involvement; Research Base; Planning Consistency; Policy Environment, and Development of Plans/Strategies. Involving a wide range of stakeholders throughout all process stages was revealed as critical to further implementation of ICM principles based on a systems approach in the Baltic States and the Russian Federation. In the longer term, the integration of ICM and maritime spatial planning into the statutory national spatial planning systems is found to be critically important.

Mestanza-Ramón et al. [12] adopt a similar approach, applying a Strengths-WeaknessesOpportunities-Threats (SWOT) analysis based on a literature review to inform future management and policy development related to beach tourism in mainland Ecuador and the Galapagos Islands. The 10 factors they considered were Policies, Regulations, Responsibilities, Institutions, Strategies and Instruments, Training, Economic Resources, Information, Education for Sustainability, and Citizen Participation. Four key aspects were highlighted as strengths, namely Policies, Responsibilities, Institutions, and Citizen Participation. The most significant weaknesses were found to be Regulations and Education for Sustainability. Strategies and Instruments, and Information, represent opportunities, whereas the threats were Economic Resources and Training. Although Ecuador developed a certification standard that establishes the requirements that beaches must meet to obtain a tourist quality certification in 2012, this norm has not yet been applied. Therefore, although Ecuador has more policies and regulation instruments regarding ICM tourism than other countries in the region, it lacks clear sustainable practices for beach tourism. By promoting 
inclusive development strategies, projects and programs, and sustaining them over time, it is considered possible to capture the benefits of one of the most dynamic economic activities in Latin America without the detrimental impacts. This would allow the implementation of a model based on respect for nature, long term sustainability and competitiveness.

Rivillas-Ospina et al. [13] also emphasize respect for nature and the people dependent on natural resources. They undertake a comprehensive assessment of the basins, islands, and wetlands of the coastal lagoon system of Ciénaga Grande de Santa Marta (CGSM), Colombia. The hydrological conditions, wave climate, and the morphological changes in the lagoon and along the coastline are found to explain the deterioration in the coastal wetlands. A three-stage hybrid project focused on restoring connectivity within the lagoon system is proposed together with a system-wide monitoring plan. The project involves the restoration of riparian vegetation, water flows, and mouth connections, mangrove forest restoration as well as a hybrid green infrastructure project incorporating an artificially constructed dune, stabilized with indigenous vegetation, and a breakwater. The authors argue that it is vital to integrate economic activities and ecosystem conservation in the management of the CGSM lagoon system-i.e., ecosystem-based management must be adopted. Such an approach can accommodate the three-staged hybrid project they propose as a means of ecosystem restoration, and facilitates the involvement of local communities in the management of the natural resources upon which they depend, enhancing coastal resilience.

Author Contributions: Writing—original draft preparation, J.S.; writing—review and editing, M.S., A.L. All authors have read and agreed to the published version of the manuscript.

Funding: This research received no external funding.

Conflicts of Interest: The authors declare no conflict of interest.

\section{References}

1. Masselink, G.; Lazarus, E. Defining Coastal Resilience. Water 2019, 11, 2587. [CrossRef]

2. van der Spek, B.; Bijl, E.; van de Sande, B.; Poortman, S.; Heijboer, D.; Bliek, B. Sandbar Breakwater: An Innovative Nature-Based Port Solution. Water 2020, 12, 1446. [CrossRef]

3. Castelle, B.; Laporte-Fauret, Q.; Marieu, V.; Michalet, R.; Rosebery, D.; Bujan, S.; Lubac, B.; Bernard, J.; Valance, A.; Dupont, P.; et al. Nature-Based Solution along High-Energy Eroding Sandy Coasts: Preliminary Tests on the Reinstatement of Natural Dynamics in Reprofiled Coastal Dunes. Water 2019, 11, 2518. [CrossRef]

4. Scheres, B.; Schüttrumpf, H. Enhancing the Ecological Value of Sea Dikes. Water 2019, 11, 1617. [CrossRef]

5. Slinger, J.; Vreugdenhil, H. Coastal Engineers Embrace Nature: Characterizing the Metamorphosis in Hydraulic Engineering in Terms of Four Continua. Water 2020, 12, 2504. [CrossRef]

6. Verhagen, H. Financial Benefits of Mangroves for Surge Prone High-Value Areas. Water 2019, 11, 2374. [CrossRef]

7. Dao, H.; Hofland, B.; Stive, M.; Mai, T. Experimental Assessment of the Flow Resistance of Coastal Wooden Fences. Water 2020, 12, 1910. [CrossRef]

8. Niazi, M.; Morales Nápoles, O.; van Wesenbeeck, B. Probabilistic Characterization of the Vegetated Hydrodynamic System Using Non-Parametric Bayesian Networks. Water 2021, 13, 398. [CrossRef]

9. Muller, J.; Chan, Y.; Piersma, T.; Chen, Y.; Aarninkhof, S.; Hassell, C.; Tao, J.; Gong, Z.; Wang, Z.; van Maren, D. Building for Nature: Preserving Threatened Bird Habitat in Port Design. Water 2020, 12, 2134. [CrossRef]

10. Maiolo, M.; Mel, R.; Sinopoli, S. A Stepwise Approach to Beach Restoration at Calabaia Beach. Water 2020, 12, 2677. [CrossRef]

11. Baltranaitè, E.; Povilanskas, R.; Dučinskas, K.; Ernšteins, R.; Tõnisson, H. Systems Approach to Eastern Baltic Coastal Zone Management. Water 2020, 12, 3102. [CrossRef]

12. Mestanza-Ramón, C.; Chica-Ruiz, J.; Anfuso, G.; Mooser, A.; Botero, C.; Pranzini, E. Tourism in Continental Ecuador and the Galapagos Islands: An Integrated Coastal Zone Management (ICZM) Perspective. Water 2020, 12, 1647. [CrossRef]

13. Rivillas-Ospina, G.; Maza-Chamorro, M.; Restrepo, S.; Lithgow, D.; Silva, R.; Sisa, A.; Vargas, A.; Sarmiento, J.; Caes, J.; Bolivar, M.; et al. Alternatives for Recovering the Ecosystem Services and Resilience of the Salamanca Island Natural Park, Colombia. Water 2020, 12, 1513. [CrossRef] 